\title{
MODELOS DE SUPORTE UTILIZADOS NO ÂMBITO DA FORMAÇÃO A DISTANCIA DE MAGISTRADOS NO CONTEXTO INTERNACIONAL
}

\author{
MODELOS DE SOPORTE UTILIZADOS EN EL ÁMBITO DE LA FORMACIÓN A \\ DISTANCIA DE MAGISTRADOS EN EL CONTEXTO INTERNACIONAL
}

\author{
SUPPORT MODELS USED IN DISTANCE TRAINING OF MAGISTRATES IN \\ THE INTERNATIONAL CONTEXT
}

Joana Matos CALDEIRA ${ }^{1}$

\begin{abstract}
RESUMO: A importância do e-learning no seio das estruturas formativas existentes nos diferentes contextos profissionais tem vindo a tornar-se crescente. Elegendo a formação online como campo de estudo, este trabalho ambiciona contribuir para a modernização das práticas formativas implementadas ao nível da formação contínua dos magistrados através da adoção das tecnologias digitais e ambientes virtuais de aprendizagem. Para o efeito, estabeleceu-se o movimento prévio de análisar os modelos pedagógicos de formação a distância adotados pelos países pertencentes à Rede Europeia de Formação Judiciária. Esta investigação foi efetuada em 2014, tendo assumido os seguintes objetivos: i) identificar práticas de formação a distância e/ou em blended-learning; ii) efetuar um levantamento das principais orientações existentes ao nível da planificação, conpceção e avaliação de ações de formação em regime a distância e/ou em blendedlearning; e iii) analisar os modelos pedagógicos adotados a este nível. Este artigo centrase na análise dos resultados inerentes ao contexto internacional, mais concretamente dos modelos de suporte utilizados no âmbito da formação a distância, com vista ao desenvolvimento de um 'state of the art' em torno da temática. Os documentos recolhidos junto a 12 países europeus constituíram um corpus de dados conceitual que nos permitiu constatar que existe um esforço estabelecido no sentido da implementação de dispositivos de formação a distância em relação à atividade formativa proporcionada aos magistrados.
\end{abstract}

PALAVRAS-CHAVE: Blended-learning. Educação a distância. Formação profissional. Magistrados.

RESUMEN: La importancia del e-learning en las estructuras formativas existentes y en los diferentes contextos profesionales sigue siendo cada vez mayor. Al elegir la formación on-line como campo de estudio, este trabajo ambiciona contribuir hacía la modernización de las prácticas formativas implementadas al nivel de la formación continua de los magistrados a través de la adopción de las tecnologías digitales y entornos virtuales de aprendizaje. Para ello, se estableció el movimiento previo de análisis de los modelos pedagógicos de formación a distancia adoptados por los países pertenecientes a la Red Europea de Formación Judicial. Esta investigación se ha realizado en 2014, habiendo asumido los siguientes objetivos: i) identificar prácticas de

${ }^{1}$ Instituto de Educação da Universidade de Lisboa, Portugal. Técnica Superior de Educação no Ministério da Defesa Nacional. Doutoranda em Educação. E-mail: joana_caldeira@hotmail.com 
formación a distancia y/o en blended-learning; ii) efectuar un levantamiento de las principales orientaciones existentes al nivel de la planificación, concepción y evaluación de acciones de formación en régimen a distancia y / o en blended-learning; $Y$ iii) analizar los modelos pedagógicos adoptados a este nivel. Este artículo se centra en el análisis de los resultados inherentes al contexto internacional, más concretamente de los modelos de soporte utilizados en el ámbito de la formación a distancia, para el desarrollo de un "state of the art" alrededor de la temática. Los documentos recogidos en 12 países europeos constituyeron un corpus de datos conceptual que nos permitió constatar que existe un esfuerzo establecido en el sentido de la implementación de dispositivos de formación a distancia en relación a la actividad formativa proporcionada a los magistrados.

PALAVRAS CLAVE: Blended-learning. Educación a distancia. Formación profesional. Magistrados.

ABSTRACT: Being aware of the importance of e-learning within the current training structures of different professional contexts, this study aims to contribute to the modernization of the training practices implemented in the continuous training of magistrates, through an analysis of the pedagogical models of distance learning adopted by the countries belonging to the European Judicial Training Network (REFJ). This research, developed in 2014, adopted the following purposes: i) to identify practices of distance learning and/or in blended-learning; ii) to carry out a survey of the main existing guidelines at the level of planning, design and evaluation of distance learning and/or blended-learning training actions; and iii) to analyze the pedagogical models adopted at this level. This article focuses on the analysis of the results inherent to the international context, specifically the support models used in distance learning so as to develop a 'state of the art', in an effort to implement a pedagogical model of distance learning. The collected documents of 12 european countries constituted a corpus of conceptual data that allowed us to verify that there is an established effort for the implementation of distance learning devices in the training activity provided to the magistrates in service.

KEYWORDS: Blended-learning. Distance learning. Professional training. Magistrates.

\section{Introdução}

A educação ao longo da vida desempenha um papel de relevo na sociedade atual, na medida em que permite aos cidadãos uma melhor adaptação às novas realidades tecnológicas e científicas, uma preparação mais adequada às necessidades laborais e um entendimento mais conveniente do mundo em que vivemos (COSTA, 2001).

Neste sentido, algumas das exigências educativas e formativas que descrevem a realidade atual apontam para a aquisição de um nível de conhecimentos de base mais 
elevado, com a finalidade de favorecer uma melhor integração no mercado de trabalho. Aos cidadãos é solicitado hoje um nível de qualificação profissional mais profundo e o confronto com o exercício de várias e sucessivas profissões ao longo da sua vida.

De acordo com estas premissas, o Conselho da União Europeia (JORNAL OFICIAL DA UNIÃO EUROPEIA, 2009, p. 2) definiu um conjunto de objetivos estratégicos no domínio da educação e formação para 2020, nomeadamente:

\begin{abstract}
"Tornar a aprendizagem ao longo da vida e a mobilidade uma realidade; Melhorar a qualidade e a eficácia da educação e da formação; Promover a igualdade, a coesão social e a cidadania ativa; Incentivar a criatividade e a inovação, incluindo o espírito empreendedor, a todos os níveis de educação e formação".
\end{abstract}

Nesta mesma linha de ideias, também o relatório da Comissão Internacional para a Educação no século XXI da UNESCO afirma que a aprendizagem ao longo da vida será uma das chaves para enfrentar os desafios educativos e formativos que se perspetivam para o futuro, fazendo com que cada indivíduo saiba conduzir o seu próprio precurso, num esforço permanente de atualização dos seus conhecimentos. Neste sentido, as tecnologias são vistas como um dos diversos fatores de transformação das estruturas sociais que contribuem de forma constante para o sucesso educativo, formativo e também profissional.

Deste modo, a crescente utilização das Tecnologias de Informação e Comunicação (TIC) tem vindo a possibilitar o surgimento de novos ambientes virtuais de suporte à aprendizagem que visam responder às necessidades da sociedade moderna, marcando um papel cada vez mais dominante e indispensável na educação, na forma de ensinar e de aprender, e essencialmente na forma de comunicar e disseminar o conhecimento.

É neste sentido que o e-learning surge, hoje em dia, como um meio manifestamente reconhecido de difusão de educação e formação e uma forma de organização da formação que pretende dar resposta aos grandes desafios no ensinoaprendizagem. Este regime de formação possibilita condições facilitadoras de acesso à educação ao longo da vida, aproveitando as oportunidades colocadas à disposição pelas TIC, tendo-se afirmado progressivamente como um complemento aos sistemas tradicionais de ensino e formação, quer do ponto de vista logístico, quer da qualidade do ensino desenvolvido, das capacidades promovidas e das atitudes e valores transmitidos. 
Assim, e perante a infinidade de abordagens e questões que se poderiam desencadear ao nível do e-learning na formação de profissionais em serviço (dada a sua complexidade e importância), impôs-se centrar a atenção deste estudo na análise dos modelos de e-learning utilizados na formação a distância pelos países pertencentes à Rede Europeia de Formação Judiciária (REFJ), considerando o contexto no qual decorreu o estudo em questão: a formação contínua de magistrados portugueses. Esta rede constitui-se como a principal plataforma promotora para o desenvolvimento, formação e intercâmbio de conhecimentos e competências do Poder Judiciário da União Europeia (UE), que desenvolve formação standard, coordena intercâmbios e programas de formação judiciária e promove a cooperação entre os organismos nacionais de formação da UE (disponível em http://www.ejtn.eu/).

\section{Contexto e objetivos de investigação}

Dado que os Estados-Membros pertencentes à REFJ partilham interesses, orientações e objetivos estratégicos ao nível da formação judiciária, considerou-se que seria de grande pertinência e relevância a análise, numa perspetiva comparada, dos modelos de suporte utilizados na formação a distância junto dos países que a constituem, de modo a melhor compreender que modelos pedagógicos é que são utilizados ao nível da formação a distância, bem como que mecanismos lhe estão subjacentes.

Tendo por base este cenário foram definidos diferentes objetivos de modo a se obter um conhecimento mais aprofundado em relação aos modelos de e-learning adotados pelas entidades formadoras responsáveis pela formação contínua de magistrados, nomeadamente: i) identificar práticas de formação totalmente a distância e/ou em blended-learning; ii) efetuar um levantamento das principais orientações existentes ao nível da planificação, conceção e avaliação de ações de formação em regime a distância e/ou em blended-learning; e iii) analisar os modelos pedagógicos adotados ao nível da formação a distância e/ou em blended-learning.

Deste modo, este artigo apresenta de forma detalhada a análise dos resultados inerentes ao contexto internacional, mais concretamente dos modelos de suporte utilizados no âmbito da formação a distância com vista ao desenvolvimento de um 'state of the art' (SOTA), tendo como propósito analisar a viabilidade e pertinência da 
implementação de um modelo pedagógico de formação a distância (blended-learning) na formação contínua de magistrados.

\section{Metodologia de investigação}

De forma a organizar e orientar a pesquisa em torno da análise dos modelos de suporte utilizados na formação a distância pelas escolas internacionais responsáveis pela formação contínua de magistrados, adotamos uma metodologia de Revisão Sistemática da Literatura (RSL), mais concretamente através da técnica de Scoping Review (SR).

A RSL constitui um método robusto de organização e avaliação, em simultâneo, de um conjunto amplo de dados provenientes da literatura científica. Esta metodologia identifica um conjunto de estudos publicados sobre um determinado tema, aqueles com qualidade metodológica comprovada e cujos resultados podem ser reproduzidos (VILELAS, 2009). A RSL é importante para integrar as informações fornecidas por um conjunto de estudos realizados separadamente em determinada área de investigação que podem apresentar resultados conflituosos ou coincidentes, bem como para identificar temas que necessitem de mais evidências, contribuindo para investigações futuras. A RSL constitui uma revisão de estudos por meio de uma abordagem sistemática, utilizando uma metodologia específica, procurando assim minimizar os erros nas respetivas conclusões. Com isso pressupõe-se que diferentes investigadores, ao seguirem os mesmos passos descritos, cheguem às mesmas conclusões.

A metodologia SR permite um conhecimento aprofundado acerca do modo como os diversos estudos se interrelacionam com a própria questão de investigação, através da identificação dos temas e pontos mais frequentes ou usuais. Esta metodologia tem sido descrita como um processo de mapeamento da literatura existente ou das evidências nesta recolhida. De forma global, Mays, Roberts e Popay (ARKSEY; O'MALLEY, 2005) referem que o objetivo da SR é mapear os conceitos de uma determinada área de investigação, identificando as principais fontes e tipos de evidências disponíveis, de modo a que os respetivos estudos de investigação possam ser vistos como projetos autonomos. Aplica-se sobretudo em áreas complexas, metodologicamente divergentes ou que ainda não foram extensivamente revistas (ARMSTRONG, 2014), como é o caso desta investigação.

A SR é uma metodologia exploratória, sendo que os resultados de todos os estudos são incluídos e consequentemente mapeados, sendo efetuado um processo de consulta, onde as temáticas mais comuns são discutidas com especialistas e com os 
diferentes intervenientes (LEVAC; COLQUHOUN; O'BRIEN, 2010). Difere habitualmente da RSL, na medida em que é um tipo específico de revisão, que pode proporcionar uma abordagem estruturada para a recolha de informação que serve de sustentação à própria RSL (ARMSTRONG, 2014). Por outras palavras, a metodologia SR difere de outras revisões, na medida em que fornece um mapeamento ou fotografia da literatura existente sem uma avaliação da qualidade dos estudos abrangidos. Esta pode funcionar tanto como uma fonte de informação para uma RSL, como, inclusive, um resultado final, podendo esta ser utilizada para identificar uma pergunta de investigação mais específica, baseada naquilo que já se sabe e naquilo que se desconhece, identificar lacunas na investigação e elencar as suas principais conclusões.

Atendendo ao que foi anteriormente referido, apresentam-se as diversas fases que um estudo de SR deve obedecer (LEVAC; COLQUHOUN; O'BRIEN, 2010), e segundo as quais se irá orientar a pesquisa em causa: i) identificar a pergunta da investigação; ii) identificar os estudos relevantes; iii) selecionar os estudos; iv) analisar graficamente os dados e v) compilar, sintetizar e reportar os resultados.

\section{Implementação}

No âmbito de um estudo desta natureza, consideramos fundamental efetuar uma análise das escolas de formação de magistrados a nível internacional, de modo a compreender de forma mais aprofundada o trabalho que tem vindo a ser desenvolvido em relação aos modelos mobilizados para desenvolvimento de formação a distância por parte das entidades responsáveis pela formação contínua de magistrados da REFJ. A constituição de um SOTA relativo às escolas de formação de magistrados a nível internacional permite obter um conhecimento mais pormenorizado acerca da formação destes profissionais, no que respeita às práticas de formação a distância, às metodologias e estratégias pedagógicas utilizadas a este nível.

Deste modo, foi enviado em 19 de junho de 2014, um e-mail (em inglês e espanhol), dirigido às entidades responsáveis pela formação de magistrados da REFJ, a solicitar informação relativas aos seguintes tópicos:

a) informações relativas a práticas de formação a distância, totalmente online ou em b-learning (semi-presencial) estabelecidas; 
b) guidelines de apoio à planificação, concepção e avaliação de ações de formação em regime totalmente a distância ou em $b$ learning;

c) modelo pedagógico adotado ao nível da formação a distância (em regime de e-learning ou b-learning);

d) outros aspetos considerados relevantes ao nível da conceção de um modelo pedagógico de formação a distância para magistrados.

De forma a conceder maior rigor e credibilidade ao estudo, foi enviada uma carta anexa ao e-mail para explicar os objetivos e intenções do estudo em questão.

Tendo em consideração as 32 escolas de formação pertencentes à REFJ, conseguimos obter um total de 12 respostas (taxa de retorno de 37,5\%), no período de tempo compreendido entre 19 de junho e 15 de julho de 2014, de acordo com a tabela seguidamente apresentada:

Tabela 1: Escolas de formação de magistrados respondentes.

\begin{tabular}{|c|c|}
\hline \multicolumn{2}{|c|}{ Rede Europeia de Formação Judiciária } \\
\hline Paises/Entidades & Escolas \\
\hline - Bélgica & -L'Institut de formation judiciaire \\
\hline - Bulgária & - National Institute of Justice \\
\hline - Croácia & - The Judicial Academy of Croatia \\
\hline -Dinamarca & $\begin{array}{l}\text { - Court } \\
\text { Administration/Domstolsstyrel sen }\end{array}$ \\
\hline -Eslováquia & - Judicial Academy of Slovakia \\
\hline -Espanha & $\begin{array}{l}\text { - Escuela Judicial Consejo General del } \\
\text { Poder Judicial }\end{array}$ \\
\hline - Holanda & - Studiecentrum Rechtspleging \\
\hline - Lituânia & - Nati onal Courts Administration \\
\hline -Polónia & $\begin{array}{l}\text { - National School of Judiciary and Public } \\
\text { Prosecution }\end{array}$ \\
\hline - REFJ & - Rede Europeia de Formação Judiciária \\
\hline - Reino Unido (Escócia) & - The Judicial Institute for Scotland \\
\hline - República Checa & - Judicial Academy \\
\hline
\end{tabular}

Fonte: Caldeira (2017)

Neste sentido e de forma a melhor sintetizar a informação remetida pelas escolas de formação acima apresentadas, optamos por organizar o material recolhido de acordo com as seguintes dimensões de análise: 
Tabela 2 - Grelha de análise e de organização do material recolhido

\begin{tabular}{|c|c|}
\hline Dimensões & Explicitacão \\
\hline 1.Conceção de $e /$ b-learning & $\begin{array}{l}\text { - Caracteriza a definição do conceito de e-learning e/ou b- } \\
\text { learning promovida no âmbito da escola de formação. }\end{array}$ \\
\hline 2.Modelo pedagógico & $\begin{array}{l}\text { - Caracteriza as principais teorias e pressupostos pedagógicos } \\
\text { adotados ao nivel do modelo pedagógico implementado. }\end{array}$ \\
\hline $\begin{array}{l}\text { 3. Forma de organização da } \\
\text { formação }\end{array}$ & $\begin{array}{l}\text { - Identifica a forma de organização da formação utilizada em } \\
\text { diferentes regimes (presencial; totalmente online ou regime de } \\
\text { e-learning; ensino que combina a vertente presencial e a } \\
\text { distância ou regime de b-learning). }\end{array}$ \\
\hline 4. Tipologia dos cursos & $\begin{array}{l}\text { - Caracteriza o tipo de ações de formação desenvolvidas (ex: } \\
\text { cursos de aperfeiçoamento, especialização, workshops, etc). }\end{array}$ \\
\hline $\begin{array}{l}\text { 5.Estrutura e organização } \\
\text { dos cursos }\end{array}$ & $\begin{array}{l}\text { - Refere a forma de or ganização e estruturação dos cursos (por } \\
\text { módulo ou unidades de aprendizagem, em função do itinerário } \\
\text { pedagógico). }\end{array}$ \\
\hline 6.Duração dos cursos & $\begin{array}{l}\text { - Identifica a carga horária total do curso e/ou do módulo ou } \\
\text { unidade de aprendizagem (consoante a estruturação do } \\
\text { itinerário pedagógico). }\end{array}$ \\
\hline 7.Tipologia das sessões & $\begin{array}{l}\text { - Enuncia o tipo de sessões utilizadas para dinamizar as ações de } \\
\text { formação (sessões presenciais - desenvolvidas em contexto de } \\
\text { sala de formação; online sincronas - em que a comunicação } \\
\text { formador/formando ocorre em simultâneo; online assincronas - } \\
\text { em que a interação formador/formando não ocorre em tempo } \\
\text { real). }\end{array}$ \\
\hline $\begin{array}{l}\text { 8.Atividades de } \\
\text { aprendizagem }\end{array}$ & $\begin{array}{l}\text { - Refere as principais atividades de aprendizagem } \\
\text { (tarefas/trabalhos individuais ou de grupo, etc) dinamizadas de } \\
\text { forma a promover a aprendizagem dos formandos e os } \\
\text { respetivos métodos e técnicas pedagógicas utilizadas. }\end{array}$ \\
\hline $\begin{array}{l}\text { 9. Recursos pedagógicos } \\
\text { utilizados }\end{array}$ & $\begin{array}{l}\text { - Menciona o tipo de recursos técnico-pedagógicos a utilizar, de } \\
\text { forma a tornar o processo de ensino-aprendizagem mais eficaz. }\end{array}$ \\
\hline $\begin{array}{l}\text { 10. Ferramentas de } \\
\text { comunicação e sistema } \\
\text { de apoio aos formandos }\end{array}$ & $\begin{array}{l}\text { - Identifica as principais ferramentas de comunicação (ex: fórum, } \\
\text { chat, etc), e sistemas de moderação utilizados para promover a } \\
\text { aprendizagem, a motivação e a participação entre os formandos } \\
\text { e os formadores ou tutores. }\end{array}$ \\
\hline $\begin{array}{l}\text { 11. Infraestrutura } \\
\text { tecnológica }\end{array}$ & $\begin{array}{l}\text { - Identifica os sistemas de gestão da aprendizagem utilizados } \\
\text { para dinamizar e gerir o processo de ensino-aprendizagem dos } \\
\text { formandos. }\end{array}$ \\
\hline $\begin{array}{l}\text { 12. Mecanismos de } \\
\text { avaliação e certificação } \\
\text { da aprendizagem }\end{array}$ & $\begin{array}{l}\text { - Identifica os momentos (avaliação diagnóstica, formativa e } \\
\text { sumativa), critérios e instrumentos de avaliação, mobilizados } \\
\text { para aferir a aprendizagem dos formandos e respetiva } \\
\text { certificação. }\end{array}$ \\
\hline $\begin{array}{l}\text { 13. Mecanismos de } \\
\text { avaliação da formação }\end{array}$ & $\begin{array}{l}\text { - Discrimina os mecanismos de avaliação e de monitorização do } \\
\text { processo formativo (avaliação da reação/satisfação, avaliação } \\
\text { do impacto, etc). }\end{array}$ \\
\hline 14. Equipa de formação & $\begin{array}{l}\text { - Descreve a composição da equipa responsável pela formação, } \\
\text { bem como dos, eventuai s, requisitos pedagógicos, técnicos e } \\
\text { profíssionais associados à mesma, de forma a garantir a } \\
\text { qualidade da atividade formativa. }\end{array}$ \\
\hline
\end{tabular}

Fonte: Caldeira 9(2017) 


\section{Resultados}

Com base na análise desenvolvida foi elaborada uma tabela comparativa, que apresenta a informação obtida relativamente às práticas estabelecidas pelas 12 entidades respondentes nas 14 dimensões de análise consideradas, de forma a se poder estabelecer um panorama geral acerca da implementação da formação a distância nos paísesmembros da REFJ.

Tabela 3: Análise comparativa dos países da REFJ

\begin{tabular}{|c|c|c|c|c|c|c|c|}
\hline & \multicolumn{7}{|c|}{ Cattegorias de analise } \\
\hline Paises & Concegio de eb-learning & Mrodelo pedag bigico & $\begin{array}{l}\text { Forma de organizazicio da } \\
\text { formanaio }\end{array}$ & Tipologia dos curros & Estrutura e organizaçac dos cursos & Duraçaio dos curros & Tipologir das sessbees \\
\hline 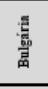 & 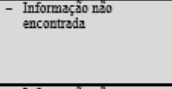 & 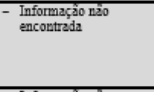 & $\begin{array}{l}\text { - Modalidade de E-learning } \\
\text { - Nodalidade hibridada }\end{array}$ & 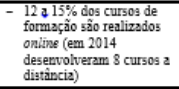 & 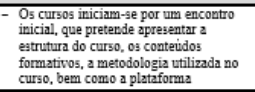 & -3.24 meses & Sessóes presenciais \\
\hline d & 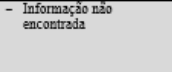 & 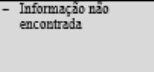 & 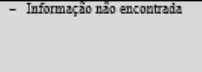 & $\begin{array}{l}\text { = Cirios } \\
\text { Oficuns }\end{array}$ & 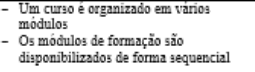 & -12 semanas & 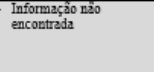 \\
\hline 虽 & $\begin{array}{l}- \text { Informargio njo } \\
\text { encoutrada }\end{array}$ & 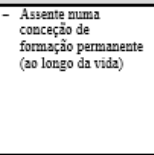 & - Informarsio nizo encontradiz & 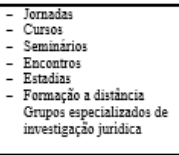 & 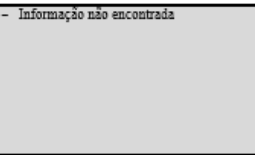 & 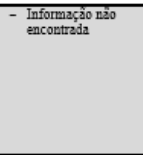 & 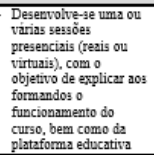 \\
\hline 吾 & - & 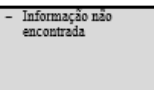 & - Informargion nzo encontrada & 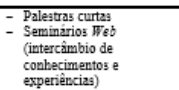 & 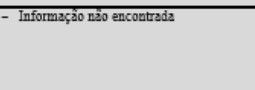 & 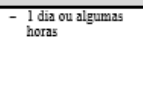 & 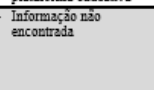 \\
\hline 哀 & 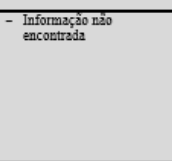 & 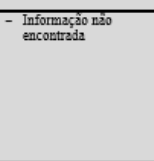 & - Modalidaded de e-jearning & 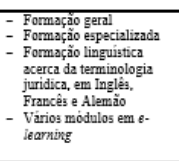 & 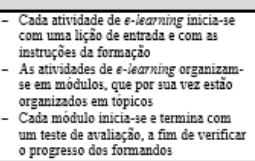 & 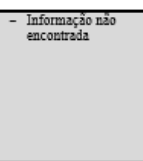 & 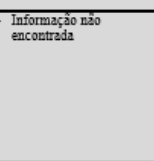 \\
\hline 䕗 & 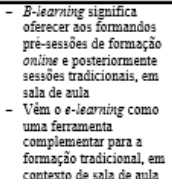 & 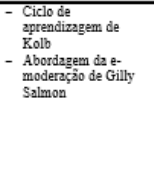 & - Modalidade de b-learning & 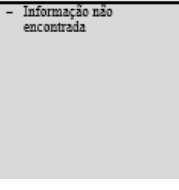 & 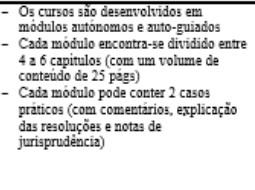 & 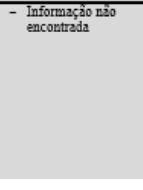 & 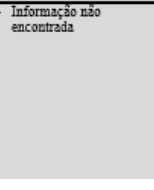 \\
\hline 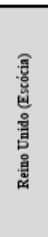 & $\begin{array}{l}\text { Tecnologia de } \\
\text { apprendizagem assistida }\end{array}$ & 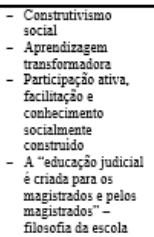 & $\begin{array}{l}\text { - Modalidade de e-iearning } \\
\text { - Nodalidade hibrida }\end{array}$ & 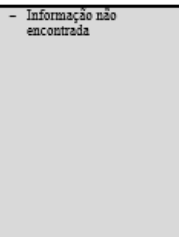 & $=$ Informaç̧o njo encontrada & 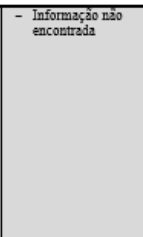 & 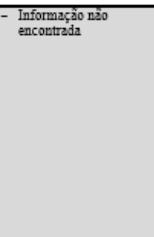 \\
\hline 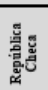 & $\begin{array}{l}- \text { Informascidi nizo } \\
\text { encoutrada }\end{array}$ & 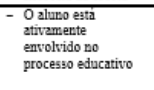 & 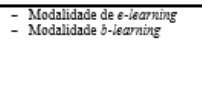 & 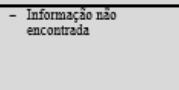 & 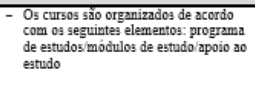 & 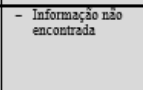 & 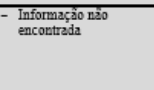 \\
\hline
\end{tabular}



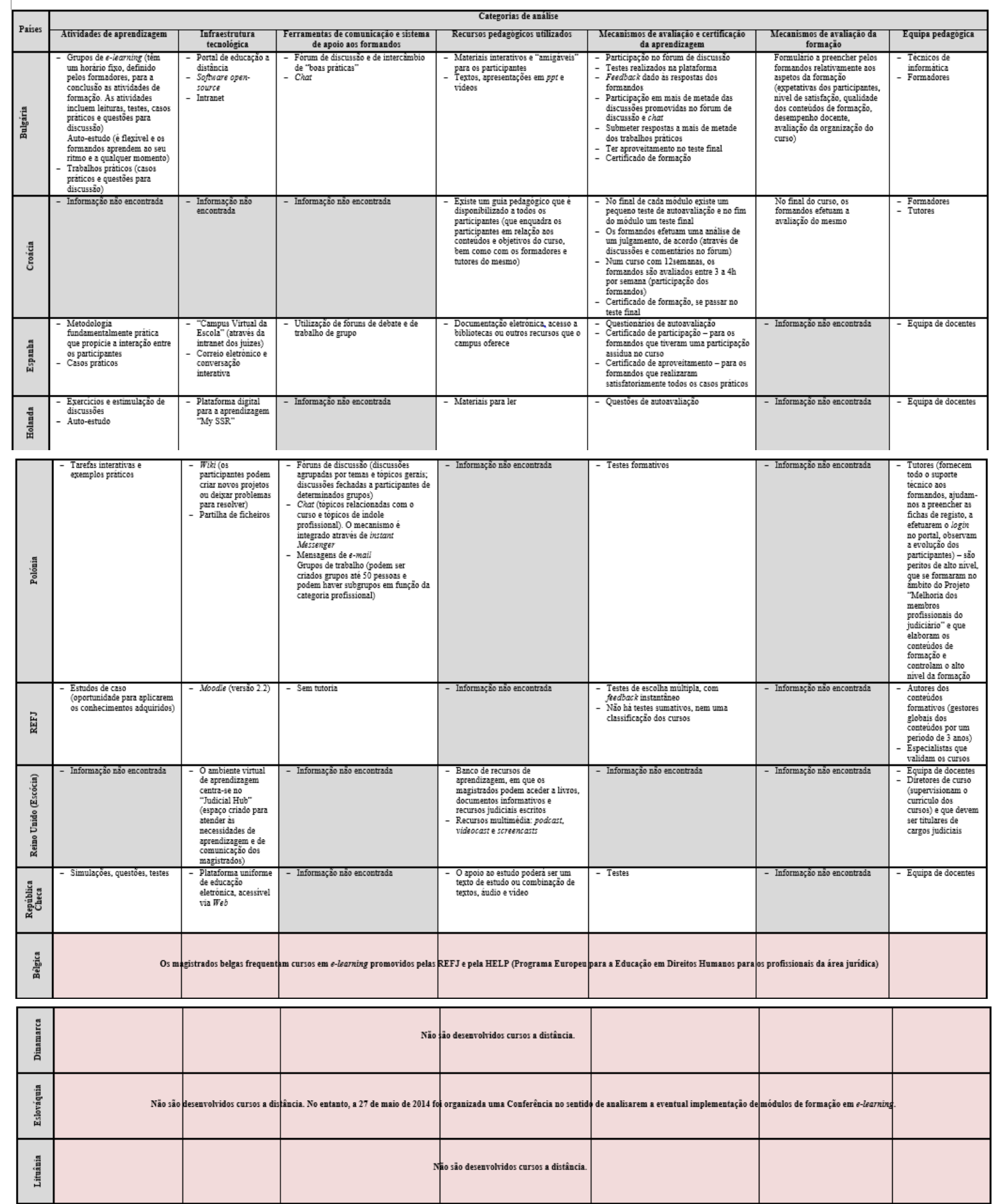

Fonte: Caldeira (2017)

Com base na tabela em causa é possível constatar que somente 3 dos 12 países (Dinamarca, Eslováquia e Lituânia) não adotam práticas de ensino a distância. Todas as restantes entidades, $75 \%$, assumem alguma tipologia de atividade formativa em regime a distância. 
Considerando as 14 dimensões de análise e, no sentido de melhor sintetizar a informação, apresentam-se seguidamente as principais conclusões, encontradas para cada uma das dimensões enunciadas na tabela 2.

Conceção de e-learning ou b-learning - a REFJ vê o e-learning como uma ferramenta complementar para a formação tradicional, e no que respeita ao regime híbrido, considera que este deve oferecer aos formandos pré-sessões de formação online e posteriormente sessões presenciais. No que respeita à Escócia, estes regimes de formação são entendidos como "regimes de aprendizagem avançada por tecnologia".

Modelo pedagógico - no que respeita às principais teorias e orientações pedagógicas adotadas pelas escolas analisadas, verifica-se uma predominante influência de modelos assentes em teorias construtivistas da aprendizagem (apoiadas no pressuposto de que o "conhecimento não se transfere, constrói-se"). Privilegia-se assim atividades de estímulo à aprendizagem ativa e participativa por parte dos formandos (Escócia e República Checa), assente numa concepção de formação permanente (Espanha), utilizando como filosofia que a "educação judicial é criada para os magistrados e pelos magistrados" (REFJ).

Forma de organização da formação - em relação ao regime de funcionamento dos cursos de formação desenvolvidos verifica-se que existem países que privilegiam apenas a formação totalmente online (Polônia) (1 em 9) ou em regime híbrido (combinando o regime de formação a distância com o presencial) (REFJ) (1 em 9) e aqueles que utilizam ambos os regimes de formação, como é o caso da Bulgária, Escócia e República Checa (3 em 9).

Tipologia dos cursos - no que respeita à tipologia dos cursos desenvolvidos esta apresenta ser muito variável, na medida em que, por um lado, são promovidos cursos de curta duração (como, por exemplo: oficinas, palestras e seminários Web), como é o caso da Croácia, Holanda e Espanha; por outro lado, são ministrados cursos de caráter mais aprofundado (por exemplo: cursos de formação geral, especialização, estadias e jornadas), como é o caso da Espanha e Polônia. Pode-se verificar que o regime de e-learning ou b-learning tende a ser adotado tanto em cursos de curta, média ou longa duração, sendo que a opção pelo regime ou duração demonstra estar mais associada aos conteúdos/temáticas abordadas, aos objetivos e dinâmicas eleitos para os mesmos do que a quaisquer outros fatores.

Estrutura e organização dos cursos - no que se refere a este tópico, encontra-se algum consenso relativamente à forma de organização e de estruturação dos cursos. A maioria das entidades formadoras (5 dos 9 organismos) organizam os seus cursos com base em módulos de formação, sendo estes por sua vez subdivididos em unidades de aprendizagem mais curtas e com uma duração aproximada (que geralmente se designam de tópicos, unidades ou temas). Em algumas situações desenvolvem-se estratégias de recepção e facilitação do processo de integração no curso, através da apresentação e estrutura genérica do curso, como se verifica em países como a Bulgária. 
Duração dos cursos - no que respeita à carga horária das atividades formativas, esta revelou ter um caráter heterogêneo em função do tipo de cursos desenvolvidos em cada escola, sendo que um curso de formação a distância pode ir de 1 dia (Holanda), até 12 semanas (Croácia) ou 3 ou 4 meses (Bulgária), não havendo um padrão de medida nem convergência em relação à duração destes cursos.

Tipologia das sessões - em relação à tipologia de sessões desenvolvidas, constata-se que tende a existir nos cursos que se realizam (total ou parcialmente) a distância, uma ou várias sessões presenciais para ambientação ao curso e para contato com o ambiente virtual de aprendizagem, sendo as restantes sessões desenvolvidas online, com momentos online síncronos (em que a comunicação formador/formando ocorre em simultâneo) e momentos online assíncronos (em que a interação formador/formando não ocorre em tempo real). Surgem como exemplo a Bulgária e Espanha.

Atividades de aprendizagem - no que respeita a esta categoria, são utilizadas metodologias essencialmente práticas, que fomentem a participação e interação dos participantes e que permitem que os mesmos aprendam ao seu ritmo e de forma autônoma. Como tal, são disponibilizadas aos formandos diferentes atividades, as quais são seguidamente enunciadas pela ordem de incidência detectada: análise e discussão online de casos práticos (em 4 dos 9 países, a saber, Bulgária, Espanha, Holanda e REFJ), simulações (em 3 dos 9 países, especificamente Holanda, República Checa), tarefas interativas (Polônia), bem como simulações e testes de verificação dos conhecimentos adquiridos (República Checa).

Recursos pedagógicos utilizados - verifica-se que, de forma a tornar a aprendizagem mais interativa e apelativa e simultaneamente mais eficaz do ponto de vista pedagógico, são utilizados diferentes recursos, designadamente: textos online (República Checa, Holanda e Bulgária), apresentações em PowerPoint, apresentações interativas, recursos multimédia (vídeos, podcast, screencast) (Bulgária, Escócia e República Checa). Verificou-se ainda que alguns países (ex.: Croácia) desenvolvem adicionalmente um guia pedagógico que é disponibilizado aos formandos e que compila toda a informação relativa ao curso de formação.

Ferramentas de comunicação e sistema de apoio aos formandos - com o objetivo de promover a motivação e a participação dos formandos são disponibilizadas atividades de aprendizagem, tais como: fóruns de discussão e chats, potenciando a comunicação com os formandos, através do debate de temas de interesse, esclarecimento de questões e dúvidas e de trabalhos de grupo (Bulgária, Polônia e Espanha). Constatou-se ainda que são utilizadas outras ferramentas de comunicação via web, nomeadamente, o correio eletrônico, como é o caso de Espanha e Polônia.

Infraestrutura tecnológica - no que respeita aos sistemas de gestão da aprendizagem utilizados pelas várias escolas, algumas entidades utilizam learning management systems não comerciais, como a plataforma Moodle (sinalizado pela REFJ). Contudo, a maioria das organizações utilizam 
plataformas customizadas ( $44 \%$ das 9 entidades, especificamente, Espanha, Escócia, Holanda e República Checa).

Mecanismos de avaliação e certificação da aprendizagem - na totalidade das entidades sob análise, a avaliação dos formandos faz parte integrante do processo formativo, tendo como finalidade validar os conhecimentos, as capacidades e as aptidões adquiridas ou desenvolvidas pelos mesmos. Assim sendo, existe por parte das entidades formadoras analisadas vários mecanismos de avaliação da aprendizagem dos formandos, quer de caráter formativo, quer sumativo. Estes vão desde a avaliação das participações em fóruns de discussão e chats (Bulgária e Croácia), à realização de tarefas solicitadas na plataforma (Bulgária), participação ativa em atividades propostas (Bulgária e Croácia) e trabalhos finais escritos, orientados sobretudo para a análise/resolução de estudos de caso (Bulgária e Croácia).

Assume especial relevo o desenvolvimento e aplicação de testes formativos e sumativos, assentes maioritariamente em questões de escolha múltipla, o que se verifica em 7 das 9 entidades, Bulgária, Croácia, Espanha, Holanda, Polônia, República Checa e REFJ. Em alguns casos, estes testes apresentam correção automática, sendo dado feedback imediato após a realização dos testes (Bulgária e REFJ), sendo os formandos imediatamente informados relativamente ao nível de aprendizagem atingido.

No que respeita à aprovação dos formandos nos cursos de formação, 3 das 9 entidades formadoras pertencentes aos países em análise referiram que concedem certificado de formação aos seus formandos (a saber, Bulgária, Croácia e Espanha), não havendo um padrão em relação à forma de avaliação dos cursos de formação.

Mecanismos de avaliação da formação - a avaliação da formação, enquanto processo de verificação da qualidade da formação, considera não só a avaliação da aprendizagem dos formandos, mas também a atividade de formação propriamente dita. Para este efeito, verifica-se a existência de mecanismos de avaliação do grau de satisfação dos participantes (formadores e formandos) em relação à ação de formação e às condições em que a mesma decorreu, visando o eventual desenvolvimento de ações de melhoria. Contudo, importa notar que apenas 2 entidades formadoras (Bulgária, Croácia) enunciaram possuir avaliação direcionada à satisfação dos formandos.

Equipa de formação - no que se refere à equipe responsável pela formação, 3 das 9 entidades formadoras referiu que a sua constituição é assegurada apenas por docentes. Contudo, houve entidades formadoras que fizeram referência à existência de outros especialistas, nomeadamente: técnicos de informática (Bulgária), tutores (Croácia, Espanha e Polônia), diretores de curso (Escócia), autores dos conteúdos formativos, especialistas científicos e especialistas em $e$ learning que validam os cursos (REFJ).

Pode-se ainda constatar que apesar destes Estados-Membros não se encontrarem todos no mesmo nível de desenvolvimento, existe um esforço estabelecido no sentido da 
implementação de dispositivos de formação a distância em relação à atividade formativa proporcionada a estes profissionais. Deste modo, e como se pode verificar através dos resultados anteriormente elencados, várias são as estratégias e atividades pedagógicas utilizadas, os recursos e ferramentas tecnológicas, os mecanismos de comunicação e de avaliação, no sentido da concretização dos objetivos pedagógicos e da consolidação do processo de ensino-aprendizagem dos magistrados.

\section{Considerações finais}

O SOTA efetuado junto das escolas internacionais de formação de magistrados revestiu-se de fundamental importância, na medida em que nos permitiu obter um conhecimento mais detalhado acerca da implementação de mecanismos de formação a distância na atividade formativa dos magistrados, bem como das práticas estabelecidas. A percepção acerca dos procedimentos pedagógicos adotados ao nível de outros modelos de formação, utilizados em contextos semelhantes, foi essencial para o estudo em questão, no sentido de perceber, em termos genéricos, as caraterísticas que lhes estavam associadas.

Neste contexto, podemos referir que de um modo geral, existem já práticas de desenvolvimento de formação a distância ao nível da formação proporcionada aos magistrados nas 12 entidades pertencentes à REFJ, sendo que três destas entidades (Bélgica, Dinamarca e Lituânia) não desenvolvem cursos de formação a distância e que outra das entidades formadoras (Eslováquia) encontrava-se a analisar a possibilidade de implementar cursos neste regime formativo.

A este nível, podemos verificar que existe por parte da REFJ um grande interesse e necessidade em adotar as tecnologias digitais e ambientes online como complemento à atividade formativa proporcionada presencialmente a esta classe profissional e como meio de uniformização das práticas e procedimentos jurídicos adotados ao nível da União Europeia. A fim de corroborar esta ideia, é importante referir que a REFJ constituiu um grupo de trabalho com elementos dos vários Estadosmembros, que, desde 2010, têm vindo a trabalhar no sentido de criar uma estratégia de formação a distância unificadora e harmonizadora entre os diferentes países que a compõem. Esta rede considera que a adoção deste regime de formação pode ser considerada como uma ferramenta metodológica muito útil, trazendo um verdadeiro 
valor acrescentado, tanto no que se refere à modalidade de formação inicial, como de formação contínua de magistrados. Todavia, a REFJ considera que este regime de formação não deve substituir totalmente a formação presencial. Defende, assim, a adoção de um regime híbrido, dada a importância do contato presencial entre pares. (REDE EUROPEIA DE FORMAÇÃO JUDICIÁRIA, 2016).

Os contínuos desenvolvimentos científicos e tecnológicos que vão surgindo exigem dos magistrados um esforço permanente de formação e desenvolvimento de novos conhecimentos e competências para poderem cumprir de forma plena com as suas funções, permitindo assim uma adaptação constante às próprias mudanças ocorridas na sociedade (PEŠTEK; KAČAPOR; RITAN, 2009).

Estas profundas alterações sociais, educativas e tecnológicas também estão a influenciar a área do direito e da magistratura em particular, havendo a necessidade de acompanhar as mudanças ocorridas, através da adoção de estratégias mais inovadoras e diversificadas, nomeadamente, através da dinamização de MOOCs (Massive Open Online Courses), de cursos em e-learning e b-learning, de sistemas de aprendizagem adaptativa (através da adaptação de um conjunto de materiais formativos às necessidades de aprendizagem específicas de cada formando) e de programas que promovam a ambientação e colaboração online entre formandos (PISTONE, 2015).

A este nível, Pistone (2015) refere que, nos Estados Unidos, as universidades na área do Direito têm vindo a trabalhar neste domínio, no sentido de criarem e partilharem, com toda a comunidade jurídica, cursos de formação que privilegiem estes regimes de aprendizagem.

Ao nível da formação de magistrados, a Comissão Europeia também partilha desta opinião. Esta, apesar de considerar que o e-learning como regime de formação eficaz ao nível da formação proporcionada aos magistrados, preconiza o regime híbrido como o efetivamente mais utilizado e de maior sustentabilidade futura, na medida em que recorre a uma metodologia de conciliação do método de formação presencial com o uso de ferramentas e ambientes digitais (EUROPEAN COMMISION, 2014).

O b-learning oferece um grande potencial para criar uma formação mais eficaz, pelo economizar de tempo e recursos financeiros às instituições de formação, pela possibilidade de tornar a formação mais estimulante e adequada às necessidades dos formandos e por proporcionar aos profissionais a oportunidade para aprender nos seus próprios contextos de trabalho. Este regime de formação combina as vantagens da formação a distância e do regime presencial, e coloca a dimensão multimédia que as 
tecnologias digitais e ambientes online trazem subjacente ao servido de aprendizagens mais interativas. O desenvolvimento das TIC tornou possível, na maioria dos países da UE, a utilização de novos instrumentos de comunicação na formação dos magistrados, de forma a facilitar o processo de ensino-aprendizagem e de rentabilizar os recursos disponíveis.

Em relação às principais vantagens associadas à combinação de regimes (presencial e online) atinentes à formação judiciária, podem referir-se as seguintes (EUROPEAN COMMISION, 2014):

- Os defensores dos cursos de formação a distância garantem que os participantes obtêm o mesmo nível de conhecimento judicial;

- Durante a formação, os participantes podem concentrar-se na aplicação prática de exercícios e no conhecimento e troca de experiências;

- Os materiais pedagógicos e o ambiente virtual de aprendizagem permanecem acessíveis, sempre que os participantes queiram consultá-los (antes e após o curso de formação);

- Os cursos de formação podem ser desenvolvidos de forma autônoma, de acordo com horários mais individualizados e flexíveis.

Neste contexto pode-se constatar que, de fato, existe uma preocupação a nível da REFJ em implementar o regime de formação a distância na formação de magistrados, bem como em adotar novas ferramentas e recursos tecnológicos e pedagógicos, no sentido de acompanhar a evolução tecnológica e de garantir a qualidade da formação desenvolvida, bem como a aquisição de conhecimentos e competências por parte dos magistrados.

\section{REFERÊNCIAS}

ARKSEY, H., O'MALLEY, L. Scoping studies: towards a methodological framework, International. Journal of Social Research Methodology, v. 8, n. 1, 2005, p. 19-32.

ARMSTRONG, et al. Cochrane update. Scoping the scope of a Cochrane review. Journal of Public Health, v. 33 n. 1, 2014, p. 147-150.

COSTA, C. Do mesmo lado do espelho. Para uma relação pedagógica eficaz. 2001. Tese de Mestrado. Faculdade de Psicologia e Ciências da Educação da Universidade de Coimbra, Coimbra, 2001. 
EUROPEAN COMMISION. Implementation of the pilot project - European Judicial Training Final Report - Lot 1 "Study on best practices in training of judges and prosecutors. Disponível em:

$<$ https://www.google.pt/\#q=Draft+Final+Report+\%E2\%80\%93+Tender+JUST\%2F201 2\%2FJUTR\%2FPR $\% 2$ F0064\%2FA4+\%E2\%80\%93+Lot+1+\%E2\%80\%9CStudy+on+b est+practices+in+training+of+judges+and+prosecutors>. Acesso em: 12 jun. 2017.

JORNAL OFICIAL DA UNIÃO EUROPEIA. Conclusões do Conselho de 12 de maio de 2009 sobre um quadro estratégico para a cooperação europeia no domínio da educação e da formação. Disponível em: <http://eur-lex.europa.eu/legalcontent/PT/ALL/?uri=CELEX:52009XG0528(01)>. Acesso em: 10 mar. 2017. LEVAC, D., COLQUHOUN, H., O'BRIEN, K. Scoping studies: advancing the methodology. 2010. Disponível em:

<http://www.implementationscience.com/content/5/1/69>. Acesso em: 22 jun. 2017.

PEŠTEK, A., KAČAPOR, K., RITAN, D. Lifelong E-Learning in Judicial Sector in Bosnia and Hercegovina, Interdisciplinary Management Research, n.V, 2009, p. 543552. Disponível em:

<http://www.efos.unios.hr/repec/osi/journl/PDF/InterdisciplinaryManagementResearch V/IMR5a44.pdf>. Acesso em: 25 jun. 2017.

PISTONE, M. Law schools and technology: where we are and where we are heading, Journal of Legal Education, v. 1006, n. 4, 2015. Disponível em:

<http://ssrn.com/abstract=2617467>. Acesso em: 27 jun. 2017.

REDE EUROPEIA DE FORMAÇÃO JUDICIÁRIA. Handbook on judicial training methodology in europe. Disponível em:

<http://www.ejtn.eu/Documents/EJTN_JTM_Handbook_2016.pdf>. Acesso em: 27 jun. 2017.

VILELAS, J. Investigação: o processo de construção do conhecimento. Lisboa, Edições Sílabo, 2009.

\section{Como referenciar este artigo}

CALDEIRA, Joana Matos. Modelos de suporte utilizados no âmbito da formação a distância de magistrados no contexto internacional. Revista Ibero-Americana de Estudos em Educação, Araraquara, v. 12, n. esp. 2, p. 1391-1407, ago./2017. Disponível em: <http://dx.doi.org/10.21723/riaee.v12.n.esp.2.10076>. E-ISSN: 19825587.

Submetido em: 08/07/2017

Aprovação final em: 18/08/2017 